Vol 13, Issue 8, 2020

\title{
COMPARISON OF EFFECTIVENESS OF STANDARD TRIPLE THERAPY VERSUS BISMUTH-BASED THERAPY FOR THE MANAGEMENT OF PEPTIC ULCER DISEASE DUE TO HELICOBACTER PYLORI
}

\section{MIRZA MISBA ALI BAIG ${ }^{1}$, UZMA PARVEEN ${ }^{1 *}$, RUQAIAH FAROOQ ${ }^{1}$, MAIMUNA TABASSUM ${ }^{1}$, FATIMA NAAZ ${ }^{1}$, SYED IBRAHIM HASSAN ${ }^{2}$}

\author{
${ }^{1}$ Department of Pharmacy Practice, Deccan School of Pharmacy, Hyderabad, Telangana, India. ${ }^{2}$ Department of Gastroenterology, Deccan \\ College of Medical Sciences, Princess Esra Hospital, Shalibanda, Telangana, India. \\ Corresponding author: Uzma Parveen. Email: uzmaparveen78641@gmail.com \\ Received: 11 April 2020, Revised and Accepted: 16 June 2020
}

\section{ABSTRACT}

Objective: Helicobacter pylori is the primary agent causing peptic ulcer, therefore imposing a significant impact on health elated quality of life, consequently affecting nearly $50 \%$ of global population. The objective of this study is to determine and assess the effectiveness of triple therapy versus bismuth containing quadruple therapy for eradication of peptic ulcer disease due to $H$. pylori.

Methods: A prospective randomized observational study was conducted at Princess Esra Hospital, Department of Gastroenterology for a period of 6 months. A total of 100 patients were randomly allocated in tow groups. The data were assessed using various parameters. $H$. pylori eradication was validated using rapid urease test done at the start treatment 4 weeks after the completion.

Results: A total of 100 patients were recruited in the study. In triple therapy group medication adherence rate was found to be $82 \%$ in triple and $92 \%$ in quadruple therapy. The eradication rate was assessed using Chi-square test it was $82 \%$ and $97 \%$ in triple and quadruple therapy group, respectively. Hence, the difference was found to be statistically significant value $<0.005$. In addition, increased recurrence rate has been observed in triple therapy (17\%) in contrast with quadruple therapy (2\%).

Conclusion: Addition of bismuth to significant triple therapy improves cure rates with minimal side effects. Interestingly, we observed that when bismuth was added, it produced a significant higher eradication rate (97\%) when compared with standard triple therapy (82\%). According to our study, bismuth is highly effective treatment of peptic ulcer disease.

Keywords: Helicobacter pylori, Peptic ulcer disease, Eradication rate, Recurrence rate.

(C) 2020 The Authors. Published by Innovare Academic Sciences Pvt Ltd. This is an open access article under the CC BY license (http://creativecommons. org/licenses/by/4. 0/) DOI: http://dx.doi.org/10.22159/ajpcr.2020.v13i8.37884

\section{INTRODUCTION}

Helicobacter pylori is one of the most prevalent pathogens which affects nearly $50 \%$ of population across the world [1,2]. Besides, the prevalence of pylori infection in India is nearly around $80 \%$ mostly occurring in rural population [3]. H. pylori primarily infects gastrointestinal (GI) tract, thereby provoking various GI diseases such as peptic ulcer disease and chronic gastritis and is also intricate in progression of cancer [4,5]. As soon as pylori resides in the stomach causing infection, it can constantly live for more than a decade in the acidic $\mathrm{pH}$ where they distort gastric mucosa, transform the secretion pattern of hormones, consequently inducing peptic ulcer disease [6].

Almost all consensus and clinical guidelines approved the use of standard triple therapy regimen consisting of proton-pump inhibitor and two antimicrobial agents as first-line therapy for eradication of pylori [7-9]. Recent research from the previous studies has concluded that the resistance to metronidazole and clarithromycin is being proliferating constantly, thereby reducing the eradication rate to $<80 \%$. Hence, the standard triple therapy is no longer effective in areas with higher antibiotic resistance. Hence, a unique antibiotic regimen is essential to further enhance eradication rate with least possible resistance.

Bismuth is a bactericidal antibiotic which causes lysis of bacteria, it is used to treat peptic ulcers and gastritis, remarkably antibiotic resistance does not occur with the usage of bismuth. Henceforth, bismuth therapy can be used as first-line therapy for successful eradication of pylori, thus improving cure rates [10]. According to Maastricht V/Florence Consensus Report 2016, PBMT therapy is recommended as firstline therapy in region where there is higher rate of clarithromycin resistance [11].

H. pylori resistance and eradication rate were assessed by Sasaki et al. from 1995 to 2008, they observed that there is a rise in resistance rate from $8.7 \%$ to $54.5 \%$ and reduction rate was reduced from $90.6 \%$ to $74.8 \%[12]$.

H. pylori infection is a typical concern among Indian population, due to rise in antibiotic resistance with triple therapy, consequently decreasing the eradication rates. We evaluated whether addition of bismuth to the standard triple therapy could be effective in terms of treatment and eradication rates. Our aim was to determine which regimen is successful for eradication of pylori.

\section{METHODS}

A prospective randomized observational study was conducted in a tertiary care hospital for a period of 6 months from November 2018 to April 2019. A total of 100 patients were randomly allocated in two groups. The demographic data, therapeutic data, laboratory data endoscopic findings, side effects, and patience compliance were collected.

The study was authorized by the Institutional Ethics Committee of Owaisi Hospital and Research Centre. This study correlates the efficacy of two different regimens, triple therapy versus bismuth containing 
quadruple therapy, administered twice daily in inpatient and outpatient of the gastroenterology department of a tertiary care hospital.

\section{Inclusion and exclusion criteria}

H. pylori positive patients were randomly allocated into two groups. Each group comprising 50 individuals.

The duration of treatment for both the groups was 14 days. The patients were entitled if they were above 18 years of age, $H$. pylori infection confirmed by rapid urease test and immunoglobulin (Ig)G and IgM antibodies test, and patients of both genders were incorporated in the study.

Patients $<18$ years of age previous surgery of GI tract, previous use of nonsteroidal anti-inflammatory drugs, known allergy to prescribed antibiotics, pregnant lactating women, history of malignancy, pediatric patients, ulcer complications, and severe comorbid conditions such as hepatic renal or cardiac disease were excluded from the study.

\section{Drug therapy used for eradication of $\boldsymbol{H}$. pylori}

The treatment included in the study consists of Regimen I - amoxicillin (750 mg) bid, clarithromycin (500 mg) bid, esomeprazole (40 mg) Regimen II - bismuth (colloidal bismuth subcitrate, $120 \mathrm{mg}$ ), esomeprazole (40 mg), clarithromycin (500 mg), amoxicillin (750 mg) bid. All drugs have been administered for a period of 14 days. Bismuth and esomeprazole were taken before meals and other antibiotics were taken after meals. Four weeks after completion of the treatment, pylori eradication rate was confirmed using rapid urease test. Negative rapid urease test indicated positive cure rates.

\section{Ethical approval}

The study was approved by the Institutional Ethics Committee of Owaisi Hospital and Research Centre. Informed consent was obtained from all subjects who participated in the study and they permitted the use of their personal information for research design.

\section{Data collection}

Patients were enrolled randomly into two groups by consecutive sampling method. We have assembled the demographic information, clinical data, side effects, compliance to treatment, rapid urease test, and endoscopic findings from all the patients who were $H$. pylori positive.

The data were collected from patient treatment chart, case sheets, laboratory reports, and patient attenders. The study required a minimum of two visits during the 6-month survey, for diagnosis of GI ulcers such as duodenal ulcer and gastric ulcer, upper endoscopy was conducted before the treatment was commenced. Rapid urease test has been used for confirmation of pylori infection. Endoscopy and rapid urease test were repeated after 14 days up to month after the termination of treatment until the status of pylori was found to be negative.

\section{Statistical analysis}

Statistical analysis was performed using SPSS software version 20.0 for Windows. For evaluation of demographic, clinical, therapeutic data in the study population, descriptive statistics were used. Outcome variables were illustrated as percentages. To determine the categorical data between two groups, Chi-square test was used. For comparison of continuous data between two groups, Student's t-test was used. $p<0.05$ is statistically significant.

\section{RESULTS}

A total of 100 patients satisfying the inclusion criteria were recruited in the study. Among 50 patients in triple therapy group, 36\% were male and $64 \%$ were female, furthermore, the most prevailing age was around 29-38 years. On the contrary, quadruple therapy group consists of $29 \%$ of male and $21 \%$ of female, the most prevailing age was around 29-38 years (Table 1 ).

Risk factors associated with peptic ulcer disease are smoking (30\%, $45 \%)$, alcohol $(18 \%, 14 \%)$, and tobacco $(26 \%, 22 \%)$, respectively, in both the groups (Table 2). The difference between the groups regarding risk factors is statistically insignificant.

A total of 34 patients completed the study in triple therapy group, 9 patients lost to follow up, and 7 patients discontinued the treatment after 6 days, henceforth, there is increased risk of recurrence of infection among these seven patients. In quadruple therapy group, 47 patients completed the treatment due to severe dyspeptic symptoms and other risk factors, 3 patients lost to follow up, and 1 patient discontinued the treatment because of side effect such as black stools (Table 3).

\section{Medication adherence}

Interestingly, in our study, we observed that medication adherence was higher in quadruple therapy as the patient consumed tablets at appropriate time due to its ability to reduce symptoms and improve prognosis of disease. Further, this prominent factor paves way for better adherence in quadruple therapy group. Even though the adherence is arithmetically higher in quadruple therapy group (92\%) when compared to triple therapy group (82\%), the results were statistically insignificant.

\section{Side effects}

The most common side effect in triple therapy group is abdominal pain, whereas in quadruple therapy group, the most common side effect is black stools.

Among 100 patients, the most common diagnosis was reflux esophagitis with erosive gastroduodenitis, erosive pangastritis and duodenitis, gastroduodenitis with duodenal ulcer, and gastroduodenitis with gastric ulcer. There was no significant difference observed between endoscopic findings in both the groups ( $p>0.05$ ) (Table 4).

\section{Eradication rates}

Rapid urease test is a non-invasive test used for distinguishing the presence of $H$. pylori. In developing countries such as India, where there is increase economic burden, these tests are needed which are cheap and accurate. The eradication rates are confirmed using rapid urease test

Table 1: Association between drug effect and clinical variables

\begin{tabular}{|c|c|c|c|c|}
\hline Variable & Triple therapy & Quadruple therapy & t-value & p-value \\
\hline Age (Mean \pm SD) & $40.0 \pm 13.82$ & $37.41 \pm 10.41$ & 1.06 & 0.12 \\
\hline Male & $18(36.00)$ & $29(58.00 \%)$ & & \\
\hline Female & $32(64.00)$ & $21(42.00)$ & & \\
\hline Risk factors & & & Odd Ratio & \\
\hline Smoking & $15(30)$ & $21(45)$ & $0.75(1.70-1.18)$ & 0.04 \\
\hline Alcohol & $4(18)$ & $7(14)$ & $1.11(1.70-1.18)$ & 0.14 \\
\hline Tobacco & $13(26)$ & $11(22)$ & $1.23(1.14-1.52)$ & 0.20 \\
\hline Dropout & $9(18)$ & $3(6)$ & $0.76(0.33-1.17)$ & 0.73 \\
\hline Eradication rate & $34(82.93)$ & 46 (97.87) & $2.18(1.17-1.18)$ & 0.05 \\
\hline Recurrence rate & $7(17.00)$ & $1(2.00)$ & $1.41(1.18-2.94)$ & 0.04 \\
\hline Negative rapid urease test & $34(82.9)$ & $46(97.7)$ & $1.22(1.00-1.28)$ & 0.21 \\
\hline
\end{tabular}


Table 2: Treatment side effects

\begin{tabular}{lllll}
\hline Side effects & $\begin{array}{l}\text { Triple } \\
\text { therapy } \\
\text { group }\end{array}$ & $\begin{array}{l}\text { Quadruple } \\
\text { therapy } \\
\text { group }\end{array}$ & Odds ratio & p-value \\
\hline Headache & 3 & 3 & 3.84 & 0.04 \\
Constipation & 4 & 5 & $(1.14-3.47)$ & \\
Abdominal pain & 5 & 3 & & \\
Pruritus & 1 & 1 & & \\
Black colored stools & 0 & 8 & & \\
\hline
\end{tabular}

Table 3: Frequency response to treatment in triple and quadruple groups

\begin{tabular}{llll}
\hline $\begin{array}{l}\text { Rapid urease test } \\
\text { post-treatment }\end{array}$ & $\begin{array}{l}\text { Triple } \\
\text { therapy }\end{array}$ & $\begin{array}{l}\text { Quadruple } \\
\text { therapy }\end{array}$ & p-value \\
\hline Positive & 7 & 1 & 0.21 \\
Negative & 34 & 46 & \\
\hline
\end{tabular}

Table 4: Endoscopic findings of the patients

\begin{tabular}{|c|c|c|c|}
\hline Endoscopic findings & $\begin{array}{l}\text { Triple therapy } \\
\text { group }\end{array}$ & $\begin{array}{l}\text { Quadruple } \\
\text { therapy group }\end{array}$ & p-value \\
\hline $\begin{array}{l}\text { Reflux esophagitis with } \\
\text { erosive duodenitis }\end{array}$ & 8 & 5 & 0.13 \\
\hline $\begin{array}{l}\text { Reflux esophagitis } \\
\text { with erosive } \\
\text { gastroduodenitis }\end{array}$ & 22 & 13 & \\
\hline $\begin{array}{l}\text { Reflux esophagitis with } \\
\text { erosive pangastritis and } \\
\text { duodenitis }\end{array}$ & 4 & 10 & \\
\hline Gastroduodenitis & 3 & 01 & \\
\hline $\begin{array}{l}\text { Reflux esophagitis with } \\
\text { gastroduodenitis and } \\
\text { duodenal ulcer }\end{array}$ & 5 & 7 & \\
\hline $\begin{array}{l}\text { Reflux esophagitis with } \\
\text { gastric and duodenal } \\
\text { ulcer }\end{array}$ & 1 & 0 & \\
\hline $\begin{array}{l}\text { Reflux esophagitis with } \\
\text { erosive gastritis and } \\
\text { duodenitis }\end{array}$ & 3 & 5 & \\
\hline $\begin{array}{l}\text { Reflux esophagitis with } \\
\text { gastritis and gastric ulcer }\end{array}$ & 3 & 5 & \\
\hline
\end{tabular}

both before and after the treatment. In our study, we observed that the eradication rates are higher in quadruple group (97\%) in comparison with triple therapy group (82\%) (Figs. 1 and 2). Henceforth, there was a significant difference in both the groups in terms of eradication rate.

\section{Recurrence rates}

This study found that after the screening of rapid urease test after 4 weeks, infection recurred in 7 patients in triple therapy group. However, we observed that there was a statistically significant difference in both the groups. p value was found to be $<0.05$ (Fig. 3).

\section{DISCUSSION}

H. pylori is the primary agent causing peptic ulcer, notably imposing a significant impact on quality of life, consequently affecting nearly $50 \%$ of global population. According to the American College of Gastroenterology regulations 2007, wherein triple therapy is proposed as the first-line agent for the management of pylori [13]. Substantial evidence from previous literature reported that the standard triple therapy does not produce acceptable eradication rates, because of rise in antibiotic resistance worldwide. Hence, other therapies such as sequential therapy, concomitant therapy, and bismuth-based quadruple therapy can be used as alternatives.

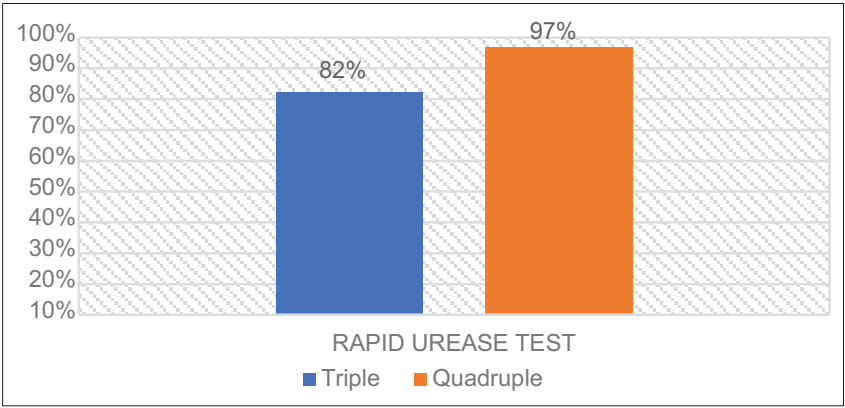

Fig. 1: Negative rapid urease test after treatment between both the groups

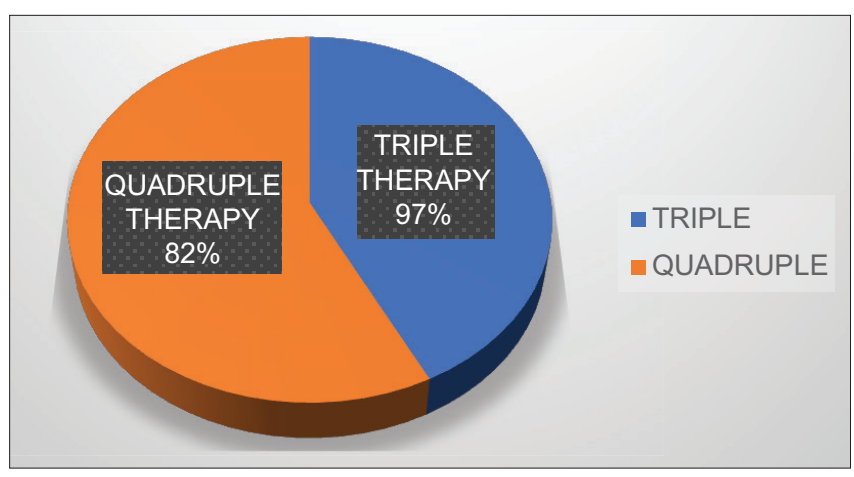

Fig. 2: Comparison of eradication rates in triple and quadruple therapy

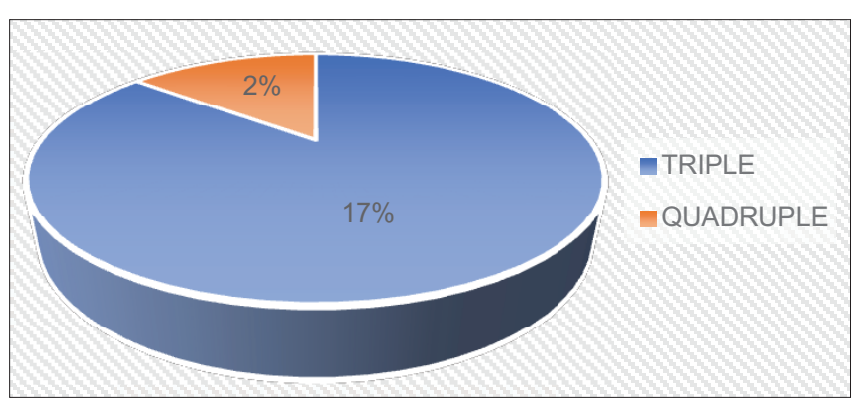

Fig. 3: Recurrence rate in both triple and quadruple therapy

Even though various studies have demonstrated the eradication rates for triple and quadruple therapy,our study particularly validates the effectiveness of bismuth use in indian population. Notably, our study validates the effectiveness of bismuth use in Indian population, further according to this study, bismuth was effective in the management of peptic ulcer disease caused by H. pylori pathogen in country like India where there is rise in antibiotic resistance. In our study, we added bismuth to standard triple therapy and compared with standard triple therapy alone which includes amoxicillin, clarithromycin, and esomeprazole. Hence, we found that on addition of bismuth, there is a significant difference in eradication rate between the two groups. We observed that bismuth produces adverse effect such as black stools in some patients, the discoloration is not permanent and is non-dangerous. The compliance to triple and quadruple regimen was found to be $82 \%$ and $92 \%$, respectively.

In Asia, the resistance to metronidazole and clarithromycin was found to be $18.9 \%$ and $37.1 \%$, respectively, and tetracycline resistance was found to be $24 \%$ [14]. Bismuth is an antimicrobial agent when used in combination with other antibiotics, it increases the eradication rate by decreasing bacterial load [15-17]. Bismuth relatively overpowers the resistance against clarithromycin $[18,19]$, metronidazole $[20,21]$, and levofloxacin $[22,23]$. 


\section{Limitations}

The time period of the study was limited. There was a lack of retrospective data for this study. In addition, we do not have data on antibiotic resistance which may influence results. The patients were randomly allocated irrespective of age, gender, and socioeconomic status.

\section{CONCLUSION}

Antibiotic resistance is a major intimidating problem in India which is contributing to rise in various $H$. pylori-related diseases, imposing a significant impact on quality of life. Hence, our study observed that on addition of bismuth to the standard triple therapy resulted in improvement of cure rates with minimal side effects. Interestingly, we observed that when bismuth was added, it produces a significant higher eradication rate $(97 \%)$ when compared with standard triple therapy $(82 \%)$. Furthermore, we achieved an acceptable medication adherence rate in both the groups; however, the medication compliance was more in quadruple therapy in comparison with triple therapy. Hence, according to our study, bismuth is highly effective in the treatment of peptic ulcer disease and can be used as first-line therapy. However, further clinical investigations are essential to determine this interpretation.

\section{ACKNOWLEDGMENT}

We would like to express our gratitude to all the patients and paramedical staff with whose support had made this study feasible. We would also like to thank Dr. Ibrahim Hassan, Professor, Head of Department of Princess Esra Hospital, and Mirza Misba Ali Baig, Asst. professor for their valuable support and guidance in carrying out the research work.

\section{AUTHORS' CONTRIBUTIONS}

Dr. Ibrahim Hassan was the principal clinical guide and treating physician for $H$. pylori patients, Mirza Ali Baig was the pharmacy guide and overall supervisor who contributed to research design, and Uzma Parveen and Ruqaiah Farooq were active in preparing the manuscript, data compilation, manuscript review, manuscript editing, and data analysis, and Maimuna Tabassum and Fatima Naaz contributed in preparing tables and references. All authors scrutinized and validated the final manuscript.

\section{CONFLICTS OF INTEREST}

The authors declare no conflicts of interest.

\section{REFERENCES}

1. Pounder RE, Ng D. The prevalence of Helicobacter pylori infection in different countries. Aliment Pharmacol Ther 1995;9:33-9.

2. Hussain SZ, Hussaini SZ, Yasmeen R, Unnisa B, Syed AA, Khan MN, et al. Comparison of efficacy and pharmacoeconomics of two helicobacter pylori eradication regimens in peptic ulcer disease. Perspect Clin Res 2018;9:4-8.

3. Abraham PH, Bhatia SJ. Position paper on Helicobacter pylori in India. Indian J Gastroenterol 1997;16 Suppl 1:S29-33.

4. Rimbara E, Fischbach LA, Graham DY. Optimal therapy for Helicobacter pylori infections. Nat Rev Gastroenterol Hepatol 2011;8:79.
5. Cardenas VM, Ortiz M, Graham DY, Gessner BD, Baggett HC, Dunaway E, et al. Helicobacter pylori eradication and its effect on iron stores: A reappraisal. J Infect Dis 2006;194:714-6.

6. Kusters JG, van Vliet AH, Kuipers EJ. Pathogenesis of Helicobacter pylori infection. Clin Microbiol Rev 2006;19:449-90.

7. Alboraie M, Saad M, Al-Ali J, Malik M, Asem N, Schmidt I, et al. Quadruple therapy versus standard triple therapy for eradication of Helicobacter pylori in Kuwait. Arab J Gastroenterol 2015;16:131-5.

8. Liou JM, Chen CC, Chen MJ, Chen CC, Chang CY, Fang YJ, et al. Sequential versus triple therapy for the first-line treatment of Helicobacter pylori: A multicentre, open-label, randomised trial. Lancet 2013;381:205-13.

9. Fischbach L, Evans EL. Meta-analysis: The effect of antibiotic resistance status on the efficacy of triple and quadruple first-line therapies for Helicobacter pylori. Aliment Pharmacol Ther 2007;26:343-57.

10. Borody TJ, Cole P, Noonan S, Morgan A, Lenne J, Hyland L, et al. Recurrence of duodenal ulcer and Campylobacter pylori infection after eradication. Med J Aust 1989;151:431-5.

11. Malfertheiner P, Megraud F, O'morain CA, Gisbert JP, Kuipers EJ, Axon AT, et al. Management of Helicobacter pylori infection the Maastricht V/Florence consensus report. Gut 2017;66:6-30.

12. Sasaki M, Ogasawara N, Utsumi K, Kawamura N, Kamiya T, Kataoka $\mathrm{H}$, et al. Changes in 12-year first-line eradication rate of Helicobacter pylori based on triple therapy with proton pump inhibitor, amoxicillin and clarithromycin. J Clin Biochem Nutr 2010;47:53-8.

13. Chey WD, Wong BC; Practice Parameters Committee of the American College of Gastroenterology. American college of gastroenterology guideline on the management of Helicobacter pylori infection. Am J Gastroenterol 2007;102:1808-25.

14. Jheng GH, Wu I, Shih HY, Wu MC, Kuo FC, Hu HM, et al. Comparison of second-line quadruple therapies with or without bismuth for Helicobacter pylori infection. Biomed Res Int 2015;2015:163960.

15. Gisbert JP, McNicholl AG. Optimization strategies aimed to increase the efficacy of $H$. pylori eradication therapies. Helicobacter 2017;22:e12392.

16. Gerrits MM, van Vliet AH, Kuipers EJ, Kusters JG. Helicobacter pylori and antimicrobial resistance: Molecular mechanisms and clinical implications. Lancet Infect Dis 2006;6:699-709.

17. Dore MP, Lu H, Graham DY. Role of bismuth in improving Helicobacter pylori eradication with triple therapy. Gut 2016;65:870-8.

18. Ozturk O, Doganay L, Colak Y, Enc FY, Ulasoglu C, Ozdil K, et al. Therapeutic success with bismuth-containing sequential and quadruple regimens in Helicobacter pylori eradication. Arab J Gastroenterol 2017; $18: 62-7$

19. Kekilli M, Onal IK, Ocal S, Dogan Z, Tanoglu A. Inefficacy of triple therapy and comparison of two different bismuth-containing quadruple regimens as a firstline treatment option for Helicobacter pylori. Saudi J Gastroenterol 2016;22:366

20. Chen Q, Zhang W, Fu Q, Liang X, Liu W, Xiao S, et al. Rescue therapy for Helicobacter pylori eradication: A randomized non-inferiority trial of amoxicillin or tetracycline in bismuth quadruple therapy. Am J Gastroenterol 2016;111:1736-42.

21. Muller N, Amiot A, Le Thuaut A, Bastuji-Garin S, Deforges L, Delchier JC. Rescue therapy with bismuth-containing quadruple therapy in patients infected with metronidazole-resistant Helicobacter pylori strains. Clin Res Hepatol Gastroenterol 2016;40:517-24.

22. Marin AC, Nyssen OP, McNicholl AG, Gisbert JP. Efficacy and safety of quinolone-containing rescue therapies after the failure of nonbismuth quadruple treatments for Helicobacter pylori eradication: Systematic review and meta-analysis. Drugs 2017;77:765-76.

23. Liao J, Zheng Q, Liang X, Zhang W, Sun Q, Liu W, et al. Effect of fluoroquinolone resistance on 14-day levofloxacin triple and triple plus bismuth quadruple therapy. Helicobacter 2013;18:373-7. 